Original Research Paper

\title{
Hand Anthropometric Data for Saudi Arabia Engineering Students of Aged 20-26 Years at King Khalid University
}

\author{
${ }^{1,2}$ Mohamed A.A. Mansour \\ ${ }^{1}$ Department of Industrial Engineering, College of Engineering, \\ Zagazig University, Zagazig, Al-Sharkia 44519, Egypt \\ ${ }^{2}$ King Khalid University, Abha, Asser, 394, Kingdom of Saudi Arabia
}

\author{
Article history \\ Received: 14-06-2016 \\ Revised: 23-09-2016 \\ Accepted: 27-09-2016 \\ Corresponding Author: \\ Mohamed A.A. Mansour \\ Department of Industrial \\ Engineering, College of \\ Engineering, Zagazig \\ University, Zagazig, Al-Sharkia \\ 44519, Egypt and \\ King Khalid University, Abha, \\ Asser, 394, Kingdom of Saudi \\ Arabia \\ Email: momansor@kku.edu.sa
}

\begin{abstract}
Anthropometric data plays a significant role in the effective and accurate design of various devices and machines. The inclusion of anthropometric data helps ensure that devices or machines are safe, userfriendly and highly productive and efficient. In this study, 56 hand dimensions based on 266 Saudi Arabian inter-university adult males aged 20-26 years are described in terms of statistics, bivariate correlations and multivariate regression models for predicting hand anthropometric dimensions. All hand dimensions were measured using the correct instruments and techniques. The statistics reported are the minimum, maximum, mean, standard deviation, percentiles (1st, 5th, 50th, 95th and 99th), normality, skewness and kurtosis. Bivariate correlations and multiple regression models are tabulated. The 56 hand dimensions of Saudi adult males are presented for use by the designers of hand tools and equipment. Most hand dimensions are positively correlated at a $0.01 / 0.05$ level of significance. Thirteen multiple regression models were developed for estimating hand length from other hand dimensions with coefficient determination factors ranging from 0.881 to 0.962 . In addition, multiple regression equations for estimating hand dimensions from hand length and breadth/fist circumference were developed. The information in this paper will be useful for ergonomic design and the modifications of hand tools, personal protective equipment, workstations and interface systems imported into Saudi Arabia to reduce human error and improve public health.
\end{abstract}

Keywords: Saudi Arabia, Hand Anthropometry, Bivariate Correlation, Hand Tool Design, Multivariate Regression Models

\section{Introduction}

The current state of the Saudi Arabian economy reveals a notable growth in the importation of machinery, vehicles, hand tools and other items manufactured in both developed and undeveloped countries. These items are designed according to the anthropometry of foreign populations, not for the Saudi population. This can be attributed to the lack of information in the literature and government databases. This mismatch between imported manmachine systems and Saudi anthropometry produces undesirable effects such as occupational disease and accidents (Okunribido, 2000; Syuaib, 2015). Aghazadeh and Mital (1987) estimated that over 260,000 injuries per year are due to worker-tool mismatches in the USA. The unavailability of properly designed machines and equipment decreases work performance and increases the chance of work injuries (Botha and Bridger, 1998).

Anthropometric data are a collection of the human body's dimensions and are used in physical anthropometry, apparel sizing and forensics. In addition, anthropometric data are applied in ergonomics to specify the physical dimensions of equipment, the workplace and furniture.

The advent of technology has completely evolved the way in which people communicate: from pigeons and telephone/telegraph/post to mobile phones (Ismaila et al., 2013; Jain, 2012; Ismaila, 2009). Today, young people use a particular type and style of mobile phone to improve their self-presentation. They prefer bigger screens with big keypads and large font displays as well as advanced touch screen handsets (Dianat et al., 2013). Thus, it is an important task to 
obtain and analyze hand anthropometric data for students aged between 20 and 26 .

While conducting this research, it was noted both that some users with long fingers find it difficult to use mobile devices while typing text messages and $96 \%$ of Saudi participants have more than one mobile. Therefore, there is a great need for a hand anthropometry database to analyze the finger and hand size of users so as to make these hand devices more user-friendly. The generalized dimensions of a user's hand between the ages of 20 and 26 will help develop accurate hand devices. Hence, the purpose of this study is to analyze the hand anthropometric data of students between the ages of 20 to 26 .

\section{Related Work}

According to Abeysekers and Shahnavaz (1989), a significance difference in anthropometric dimensions among populations leads to a mismatch between imported products/tools and people in other countries. For example, a European adjustable helmet did not properly fit $40 \%$ of heads in Sri Lanka. The availability of anthropometric data is one of the most important factors for designing manmachine systems that have greater interaction ability and safety as well as higher performance and productivity (Lewis and Narayan, 1993).

Anthropometric data for the Saudi Arabian population are to some degree limited in the literature. A few researchers have emphasized the effect of cardiovascular performance on the anthropometric growth of school boys and girls (Noweir et al., 2001; Al-Hazzaa, 1990). Alrashdan et al. (2014) gathered 32 body dimensions and the weight of 152 female students, aged 18-25 years, from different female campuses in Riyadh, the capital of Saudi Arabia. They considered hand length and width and presented anthropometric tables, comparing the dimensions of Saudi females with those of Western and Asian populations. In addition, to the best of our knowledge, there is no anthropometric database available for Saudi Arabians from the Saudi Arabia Standards Organization.

There are data for different populations in the Middle East; for instance, there are data for Jordanians (Mohammad, 2005), static anthropometry for Iranians (Dianat et al., 2013; Mirmohammadi et al., 2016), anthropometry for the design of Bahraini school furniture (Mokdad and Al-Ansari, 2009) and anthropometric measurements of Turkish adults (Ali and Arslan, 2009). Various hand anthropometry studies have been performed to develop anthropometric databases, design machinery and hand tools, study the variations existing in ethnic subpopulations for comparative study and study hand performance. The populations in these studies were industrial workers, adult civilians, farmers (García-
Cáceres et al., 2012), university students, primary school students and adult military personnel. The number of hand dimensions' ranges from one to 86 dimensions, the sample size ranges from 23 to 2,387 subjects and age ranges from five to 11 years for students and 15 to 80 years for adults. Some hand anthropometric data are available in the literature for nations such as the UK, Sweden, Spain, Colombia, Thailand, Jordan, Nigeria, Norway, the USA, China and Sri Lanka.

Some studies point out the importance of anthropometric data for machine design. Wagner (1988) compiled data on 20 hand dimensions for pianists and pointed out the significance of these measurements for keyboard design. Nag et al. (2003) described data for 51 hand dimensions from 95 Indian women in their study of ergonomic hand tool design. Mandahawi et al. (2008) collected data on 24 hand dimensions relevant to tool design for 115 men and 120 women from four Jordanian cities and compared this data with those of other populations. Research on this topic includes the work done by Kar et al. (2003), Meagher (1987; 1989, Schmidtke (1984) and Norris and Wilson (1997).

In addition to these studies, some research that is relevant to the design of hand tools for various nationalities has been published. Davies et al. (1980a) described 28 hand dimensions for female industrial workers from the UK to evaluate the standards of machine guards. Imrhan and Contreras (2005) described 23 hand dimensions based on two samples consisting of 25 men and 25 women for Mexicans living near the USA border including workers, university students and home helpers. Buchholz et al. (1992) and Buchholz and Armstrong (1991) studied the interaction of handle size and shape with kinematics and hand anthropometry.

Other studies focused on developing an anthropometric database for various developed and undeveloped countries and comparisons among ethnic sub-populations. Okunribido (2000) conducted an anthropometric survey measuring 18 dimensions of the right hand in 37 female rural farm workers living in Ibadan, Western Nigeria. The statistics for collecting data were compared with those for females from the UK, Hong Kong and the USA using data from other published studies. He concluded that the Nigerian female hand is wider and thicker, but shorter than that of their foreign counterparts. Davies et al. (1980b) compared 28 hand anthropometric dimensions based on a sample of 92 subjects for three ethnic groups. Greiner (1991) collected data about 86 hand dimensions for USA Army personnel.

Cakit et al. (2012) conducted a hand survey and biomechanical measurements of dentistry students in Turkey. Thirty-three hand dimensions were measured and described using statistical measures for 92 male and 73 female students studying at dentistry faculty 
and compared with Thai, Indian, Malaysian, British, Jordanian, Nigerian, Mexican, Bangladesh and Vietnamese populations. Kember et al. (1981) conducted a hand anthropometric survey of UK workers for 12 dimensions. Sutjana et al. (2008) measured 46 body dimensions, which includes seven hand measurements, of 127 medical students in Indonesia and calculated the mean and standard deviations, as well as the 5th, 50th and 95th percentiles.

Abeysekera and Shahnav (1988) measured 85 anthropometric body measurements and derived another five for 724 Sri Lankan workers. They compared hand length, hand width and both measurements with other populations such as those of Western Europe, West India, India (Punjab), Hong Kong China, the UK, Japan, Africa/Sudan, Sri Lanka, Sweden and Egypt. Ahn et al. (2016) studied the effect of grip curvature and hand anthropometry for the unimanual operation of touch screen handheld devices. Irwin and Radwin (2008) estimated the internal biomechanical loads of the hand from external loads and finger lengths that were themselves estimated from measured hand length and breadth. They found that hand anthropometric measurements, especially palm width, are better predictors of hand strength than stature and body weight. An important implication of the above discussion is that hand anthropometry must be known for any target population for whom hand tools and other manual devices are to be designed.

Courtney (1984) carried out a hand anthropometric study of on a sample of 100 Hong Kong Chinese female workers and summarized 23 hand dimensions, comparing the results with data from the UK, Japan and the USA. The study indicated significant differences for age and ethnic group. Further, Claudon (2000) discussed how poor ergonomic hand tool design is a well-known factor contributing to biomechanical stresses and increasing the risk of cumulative trauma and carpal tunnel syndrome disorders. Bures et al. (2015) developed a hand anthropometric database for the Czech population and Obi (2016) developed a hand anthropometry survey for rural farm workers in Southeastern Nigeria.

Abeysekera and Shahnavaz (1989) noted that the potentially harmful effects of ignoring anthropometric differences among populations may manifest, for example, when a developing nation imports equipment from a developed nation because the latter tends to design their equipment based on the anthropometric data on their own population. Reliable data on the association between hand injuries or disorders and hand anthropometry are almost absent in developing countries. According to Kar et al. (2003), the continued reliance on muscular power for tool use, in developing countries and the widespread use of hand tools that do not fit hands properly results in health, safety and task performance problems. Further information on the relevant anthropometric dimensions of the populations of importing countries for equipment design may help reduce these problems. Limited work has addressed hand anthropometry data for the populations of developing countries (Abeysekera 1988; Imrhan et al., 2006; 2009; Chandra et al. 2011).

The reviewed literature indicates that no research focusing on hand anthropometry for the Saudi Arabian people has yet been conducted. Hence, the present study is the first comprehensive hand anthropometric study in general for Saudi Arabians and in particular for engineering students. This paper presents the results of a hand anthropometric study of a sample of 266 male adults enrolled in engineering programs at King Khalid University (KKU). A bivariate correlation analysis and multivariate regression model for predicting hand length is estimated in this article. The results of this study are expected to influence the design and choice of hand tools imported into Saudi Arabia and provide the impetus for more anthropometric studies on Saudi people that relate to the design of equipment and other activities.

\section{Materials and Methods}

\section{Subjects}

The anthropometric data for 266 male participants were collected during the winter of 2015 at KKU, Abha, Aseer Region, Kingdom of Saudi Arabia. The participants were engineering students from various provinces in Aseer, which is in the southwest of the Kingdom. The subjects were enrolled on a voluntary basis in this research. All had normal physical health and were free of any medical contraindications. The average and standard deviation for the height, weight and age of the male subjects were $(166.95,7.59) \mathrm{cm},(65.57,8.23) \mathrm{kg}$ and $(22.89,0.98)$ years, respectively. Knowledge related to diseases, which affects the characteristics of anthropometric data, was considered an exclusion criterion, as identified by Malina and Bushang (1984).

\section{Hand Dimensions}

All measurements were conducted on right-handed individuals based on a performance index greater than 0.85 according to Annett (1970). Fifty-six hand dimensions were measured, as specified in Fig. 1 and Table 1, according to Garrett (1970) and Ermacova et al. (1985).

\section{Instruments}

A 60-inch anthropometric tape, finger circumference gauge model F00575, large anthropometer model 01290 and small anthropometer model 01291 were used. All instruments were produced by the Lafayette Instrument Company (USA). 

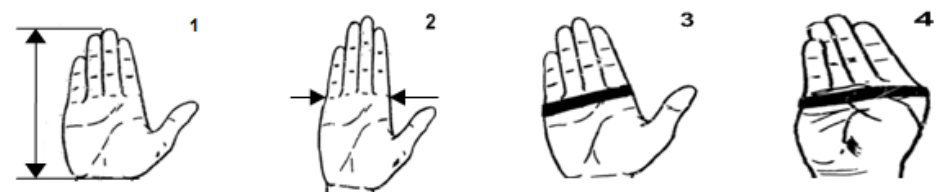

${ }^{2}$
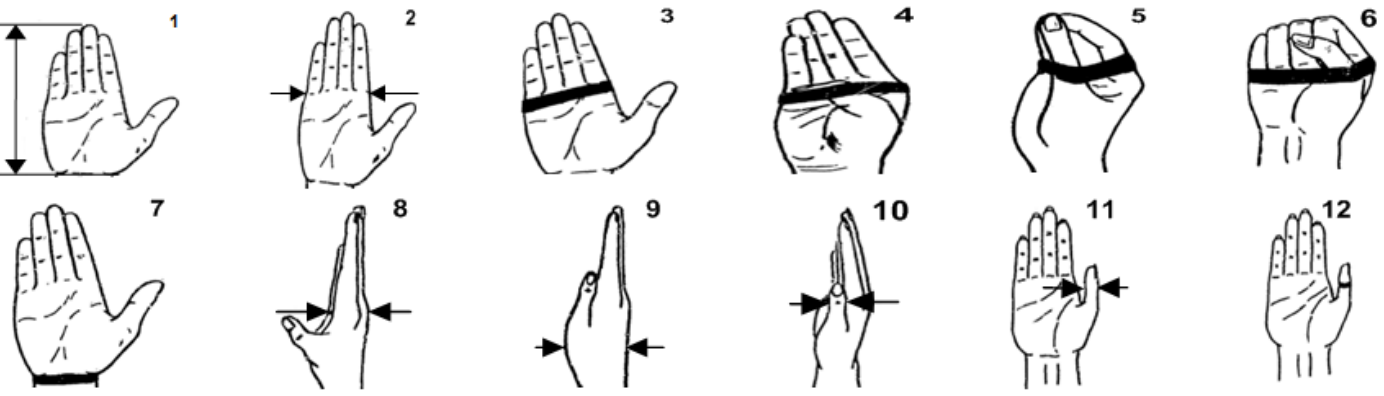

橵

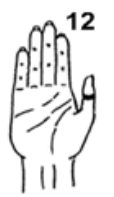

$\rightarrow$
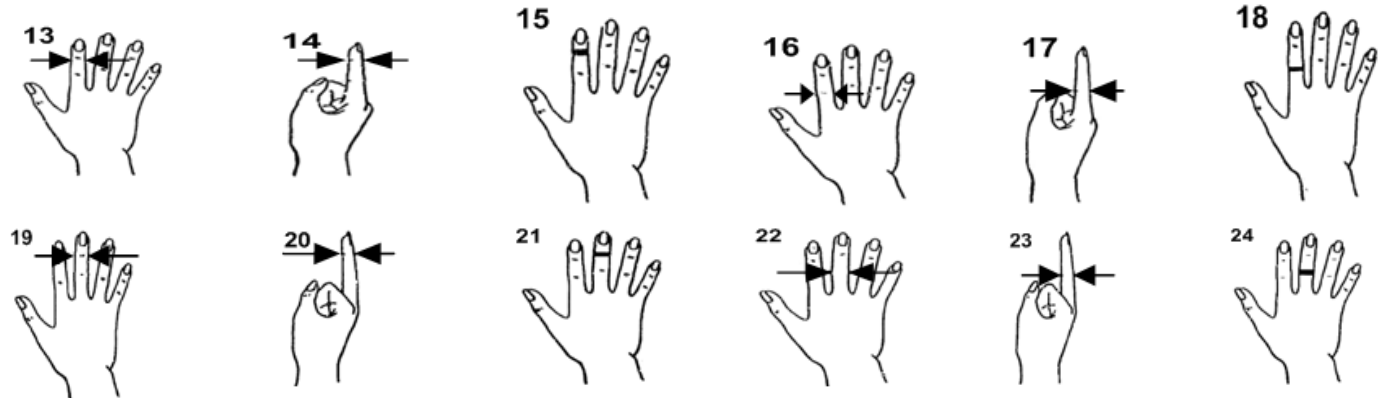

$21 \%$

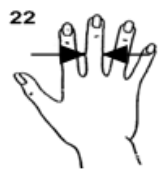

(t)

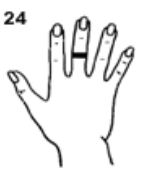

25
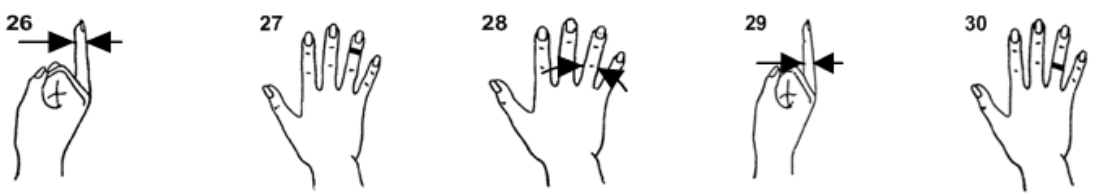

$N^{31}$
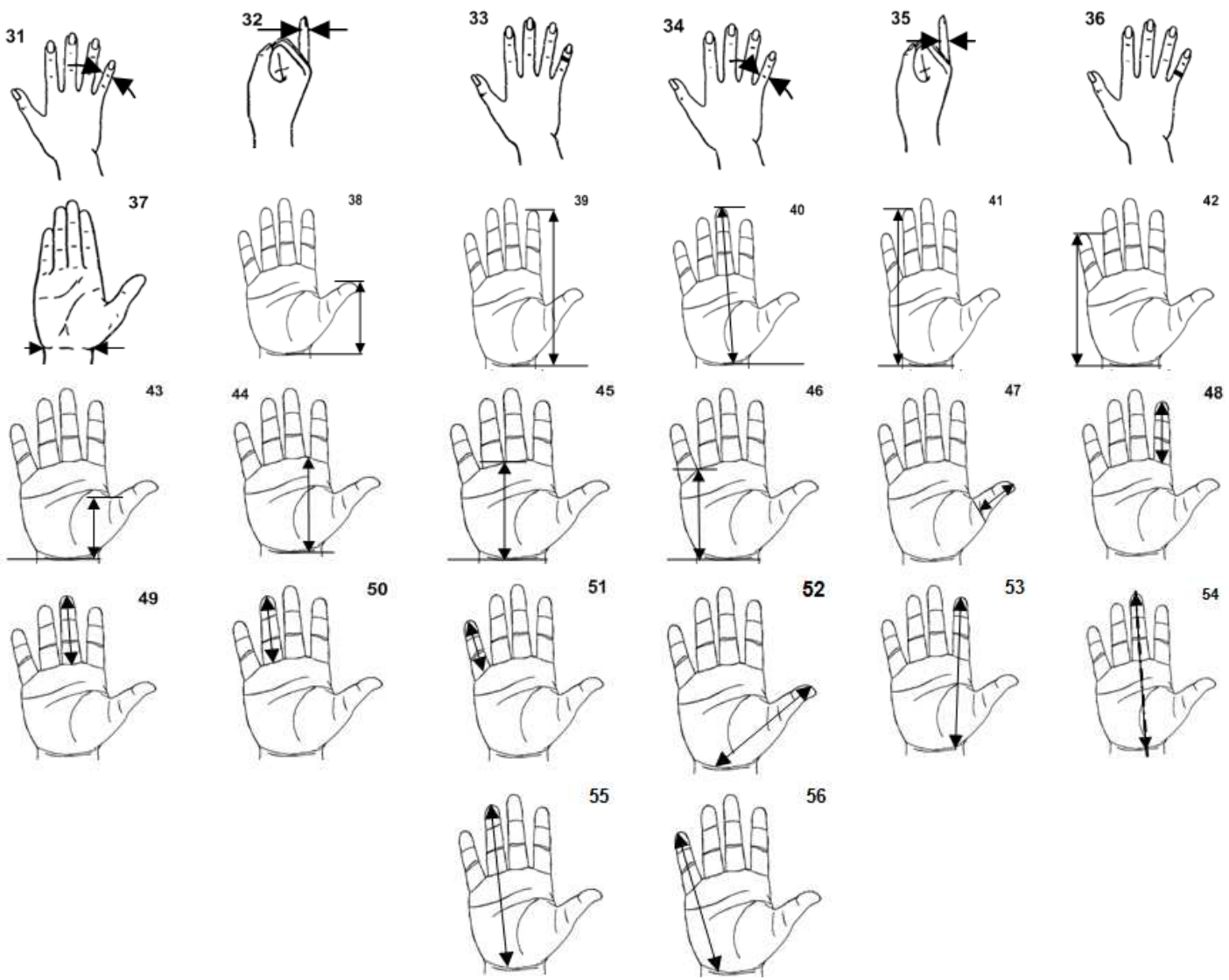

Fig. 1. Hand dimensions measured in the study 
Table 1. Descriptive statistics of 56 hand anthropometric dimensions

\begin{tabular}{|c|c|c|c|c|c|c|c|c|c|c|c|c|c|}
\hline \multirow[b]{2}{*}{ Code } & \multirow[b]{2}{*}{ Dimension } & \multicolumn{2}{|l|}{ Range } & \multirow[b]{2}{*}{ Mean } & \multirow[b]{2}{*}{ SD } & \multicolumn{5}{|c|}{ Percentiles } & \multirow[b]{2}{*}{ SW } & \multirow[b]{2}{*}{ Sk } & \multirow[b]{2}{*}{$\mathrm{Ku}$} \\
\hline & & Min & Max & & & $1 \mathrm{st}$ & 5 th & 50 th & 95 th & 99th & & & \\
\hline$\overline{\text { D1 }}$ & Hand length & 16.06 & 20.24 & 17.87 & 0.78 & 16.09 & 16.59 & 17.90 & 19.16 & 19.81 & 0.68 & 0.04 & -0.24 \\
\hline D2 & Hand breadth at metacarpal & 6.69 & 8.66 & 7.67 & 0.35 & 6.90 & 7.08 & 7.69 & 8.26 & 8.55 & 0.73 & -0.01 & 0.04 \\
\hline D3 & Hand circumference at metacarpal & 16.46 & 20.60 & 18.63 & 0.74 & 16.79 & 17.25 & 18.63 & 19.83 & 20.36 & 0.56 & -0.11 & 0.11 \\
\hline D4 & Hand circumference at metacarpal, minimum & 17.97 & 24.62 & 21.30 & 1.12 & 18.81 & 19.52 & 21.32 & 23.26 & 23.96 & 0.92 & 0.12 & -0.12 \\
\hline D5 & Hand circumference, fingertips even & 19.46 & 25.50 & 22.48 & 1.08 & 19.71 & 20.62 & 22.56 & 24.15 & 24.98 & 0.39 & -0.20 & 0.00 \\
\hline D6 & Fist circumference & 21.77 & 27.49 & 24.75 & 1.15 & 22.31 & 22.90 & 24.77 & 26.75 & 27.38 & 0.19 & 0.12 & -0.43 \\
\hline D7 & Wrist circumference & 12.90 & 16.61 & 14.92 & 0.66 & 13.45 & 13.85 & 14.93 & 15.99 & 16.49 & 0.79 & -0.03 & -0.20 \\
\hline D8 & Hand thickness, metacarpal 3 & 2.26 & 3.23 & 2.76 & 0.17 & 2.30 & 2.48 & 2.76 & 3.05 & 3.18 & 0.71 & -0.07 & 0.16 \\
\hline D9 & Hand depth, thenar pad & 4.15 & 6.12 & 5.12 & 0.37 & 4.24 & 4.47 & 5.12 & 5.74 & 6.00 & 0.80 & -0.07 & -0.03 \\
\hline D10 & Digit 1: Interphalangeal joint breadth & 1.56 & 2.25 & 1.89 & 0.12 & 1.61 & 1.71 & 1.89 & 2.09 & 2.15 & 0.83 & 0.06 & -0.05 \\
\hline D11 & Digit 1: Interphalangeal joint depth & 1.35 & 1.94 & 1.65 & 0.11 & 1.39 & 1.50 & 1.65 & 1.84 & 1.91 & 0.40 & 0.12 & -0.13 \\
\hline D12 & Digit 1: Interphalangeal joint circumference & 4.67 & 6.42 & 5.59 & 0.30 & 4.81 & 5.11 & 5.59 & 6.12 & 6.29 & 0.70 & 0.08 & -0.03 \\
\hline D13 & Digit 2: Distal interphalangeal joint breadth & 1.31 & 1.79 & 1.53 & 0.10 & 1.32 & 1.38 & 1.53 & 1.69 & 1.75 & 0.15 & 0.11 & -0.55 \\
\hline D14 & Digit 2: Distal interphalangeal joint depth & 1.00 & 1.49 & 1.22 & 0.08 & 1.03 & 1.08 & 1.23 & 1.35 & 1.44 & 0.67 & 0.02 & -0.05 \\
\hline D15 & Digit 2: Distal interphalangeal joint circumference & 3.84 & 5.25 & 4.43 & 0.25 & 3.87 & 4.00 & 4.45 & 4.84 & 4.96 & 0.16 & -0.05 & -0.35 \\
\hline D16 & Digit 2: Proximal interphalangeal joint breadth & 1.55 & 2.06 & 1.81 & 0.09 & 1.60 & 1.67 & 1.82 & 1.97 & 2.03 & 0.52 & 0.03 & -0.39 \\
\hline D17 & Digit 2: Proximal interphalangeal joint depth & 1.40 & 1.85 & 1.62 & 0.09 & 1.41 & 1.48 & 1.61 & 1.77 & 1.83 & 0.69 & 0.13 & -0.26 \\
\hline D18 & Digit 2: Proximal interphalangeal joint circumference & 4.75 & 6.04 & 5.39 & 0.26 & 4.79 & 4.97 & 5.39 & 5.82 & 6.02 & 0.48 & 0.03 & -0.36 \\
\hline D19 & Digit 3: Distal interphalangeal joint breadth & 1.27 & 1.72 & 1.53 & 0.09 & 1.35 & 1.38 & 1.53 & 1.66 & 1.71 & 0.06 & -0.17 & -0.44 \\
\hline D20 & Digit 3: Distal interphalangeal joint depth & 1.04 & 1.55 & 1.31 & 0.09 & 1.09 & 1.16 & 1.31 & 1.47 & 1.52 & 0.46 & 0.00 & -0.13 \\
\hline D21 & Digit 3: Distal interphalangeal joint circumference & 3.91 & 5.18 & 4.48 & 0.25 & 3.94 & 4.06 & 4.49 & 4.88 & 5.10 & 0.48 & 0.02 & -0.32 \\
\hline D22 & Digit 3: Proximal interphalangeal joint breadth & 1.60 & 2.09 & 1.83 & 0.09 & 1.63 & 1.67 & 1.83 & 1.97 & 2.07 & 0.34 & 0.12 & -0.30 \\
\hline D23 & Digit 3: Proximal interphalangeal joint depth & 1.41 & 1.94 & 1.66 & 0.10 & 1.42 & 1.49 & 1.66 & 1.82 & 1.90 & 0.55 & -0.04 & -0.38 \\
\hline D24 & Digit 3: Proximal interphalangeal joint circumference & 4.81 & 6.24 & 5.48 & 0.24 & 4.94 & 5.09 & 5.47 & 5.88 & 6 & 0.79 & 0.16 & -0.06 \\
\hline D25 & Digit 4: Distal interphalangeal joint breadth & 1.18 & 1.68 & 1.43 & 0.09 & 1.22 & 1.28 & 1.43 & 1.57 & 1.61 & 0.81 & -0.02 & -0.23 \\
\hline $\mathrm{D} 26$ & Digit 4: Distal interphalangeal joint depth & 1.01 & 1.55 & 1.25 & 0.09 & 1.04 & 1.09 & 1.25 & 1.39 & 1.48 & 0.66 & 0.11 & 0.02 \\
\hline $\mathrm{D} 27$ & Digit 4: Distal interphalangeal joint circumference & 3.65 & 4.81 & 4.21 & 0.24 & 3.68 & 3.85 & 4.21 & 4.61 & 4.77 & 0.20 & 0.14 & -0.41 \\
\hline $\mathrm{D} 28$ & Digit 4: Proximal interphalangeal joint breadth & 1.45 & 1.95 & 1.68 & 0.09 & 1.46 & 1.53 & 1.69 & 1.83 & 1.89 & 0.48 & -0.05 & -0.26 \\
\hline D29 & Digit 4: Proximal interphalangeal joint depth & 1.33 & 1.87 & 1.57 & 0.10 & 1.34 & 1.40 & 1.56 & 1.75 & 1.80 & 0.65 & 0.09 & -0.26 \\
\hline D30 & Digit 4: Proximal interphalangeal joint circumference & 4.55 & 5.64 & 5.10 & 0.23 & 4.58 & 4.72 & 5.09 & 5.50 & 5.61 & 0.21 & 0.06 & -0.47 \\
\hline D31 & Digit 5: Distal interphalangeal joint breadth & 1.10 & 1.56 & 1.31 & 0.09 & 1.12 & 1.16 & 1.30 & 1.44 & 1.51 & 0.23 & 0.11 & -0.27 \\
\hline D32 & Digit 5: Distal interphalangeal joint depth & 0.88 & 1.36 & 1.13 & 0.08 & 0.91 & 0.99 & 1.13 & 1.26 & 1.33 & 0.96 & -0.04 & 0.03 \\
\hline D33 & Digit 5: Distal interphalangeal joint circumference & 3.28 & 4.48 & 3.85 & 0.23 & 3.32 & 3.50 & 3.85 & 4.24 & 4.45 & 0.30 & 0.16 & -0.23 \\
\hline D34 & Digit 5: Proximal interphalangeal joint breadth & 1.21 & 1.66 & 1.45 & 0.09 & 1.23 & 1.30 & 1.46 & 1.59 & 1.63 & 0.28 & -0.17 & -0.25 \\
\hline D35 & Digit 5: Proximal interphalangeal joint depth & 1.16 & 1.65 & 1.39 & 0.08 & 1.21 & 1.26 & 1.39 & 1.52 & 1.58 & 0.64 & 0.05 & -0.19 \\
\hline D36 & Digit 5: Proximal interphalangeal joint circumference & 3.91 & 4.99 & 4.46 & 0.23 & 3.96 & 4.08 & 4.45 & 4.85 & 4.95 & 0.06 & 0.09 & -0.70 \\
\hline D37 & Wrist breadth & 4.88 & 6.58 & 5.81 & 0.32 & 4.94 & 5.25 & 5.81 & 6.31 & 6.54 & 0.66 & -0.14 & -0.14 \\
\hline D38 & Digit 1:Height, pe & 6.37 & 10.98 & 8.56 & 0.84 & 6.62 & 7.12 & 8.59 & 9.98 & 10.39 & 0.67 & -0.09 & -0.19 \\
\hline D39 & Digit 2:Height, perpendicular to wrist crease & 14.17 & 18.64 & 16.34 & 0.84 & 14.22 & 14.85 & 16.37 & 17.62 & 18.12 & 0.56 & -0.17 & -0.23 \\
\hline D40 & Digit 3:Height, perpendicular to wrist crease & 15.41 & 19.41 & 17.56 & 0.79 & 15.58 & 16.12 & 17.62 & 18.90 & 19.32 & 0.59 & -0.13 & -0.22 \\
\hline D41 & Digit $4:$ Height, $p$ & 14.03 & 18.21 & 16.29 & 0.81 & 14.23 & 15.00 & 16.28 & 17.68 & 18.14 & 0.64 & -0.02 & -0.18 \\
\hline D42 & Digit 5:Height, perpendicular to wrist crease & 10.56 & 15.03 & 12.94 & 0.83 & 11.00 & 11.60 & 12.95 & 14.40 & 14.93 & 0.91 & 0.04 & -0.24 \\
\hline D43 & Crotch 1 height & 4.37 & 7.16 & 5.68 & 0.58 & 4.44 & 4.72 & 5.70 & 6.71 & 7.02 & 0.32 & 0.10 & -0.35 \\
\hline D44 & Crotch 2 height & 8.34 & 11.44 & 9.80 & 0.60 & 8.44 & 8.78 & 9.77 & 10.81 & 11.40 & 0.60 & 0.08 & -0.19 \\
\hline D45 & Crotch 3 height & 8.09 & 11.20 & 9.78 & 0.57 & 8.46 & 8.92 & 9.78 & 10.73 & 11.10 & 0.55 & 0.03 & -0.19 \\
\hline D46 & Crotch 4 height & 7.07 & 10.10 & 8.67 & 0.59 & 7.21 & 7.74 & 8.66 & 9.66 & 9.96 & 0.52 & 0.03 & -0.27 \\
\hline D47 & Digit 1: Length, fingertip to crotch level & 4.32 & 6.66 & 5.35 & 0.46 & 4.42 & 4.59 & 5.31 & 6.16 & 6.39 & 0.21 & 0.18 & -0.36 \\
\hline D48 & Digit 2: Length, fingertip to crotch level & 5.76 & 8.29 & 6.82 & 0.46 & 5.84 & 6.03 & 6.85 & 7.62 & 7.83 & 0.24 & 0.06 & -0.26 \\
\hline D49 & Digit 3: Length, fingertip to crotch level & 6.64 & 9.06 & 7.78 & 0.48 & 6.76 & 6.98 & 7.77 & 8.56 & 8.83 & 0.08 & 0.03 & -0.58 \\
\hline D50 & Digit 4: Length, fingertip to crotch level & 5.95 & 8.75 & 7.32 & 0.47 & 6.16 & 6.60 & 7.30 & 8.16 & 8.37 & 0.84 & 0.06 & -0.01 \\
\hline D51 & Digit 5: Length, fingertip to crotch level & 4.38 & 6.55 & 5.44 & 0.40 & 4.57 & 4.80 & 5.42 & 6.13 & 6.44 & 0.51 & 0.19 & -0.20 \\
\hline D52 & Digit 1: Length, total, tip to wrist crease & 8.96 & 13.69 & 10.95 & 0.96 & 9.02 & 9.19 & 10.96 & 12.61 & 13.45 & 0.05 & 0.17 & 0.10 \\
\hline D53 & Digit 2: Length, total, tip to wrist crease & 14.35 & 18.59 & 16.59 & 0.83 & 14.83 & 15.12 & 16.57 & 18.05 & 18.44 & 0.29 & -0.06 & -0.35 \\
\hline D54 & Digit 3: Length, total, tip to wrist crease & 15.43 & 20.06 & 17.61 & 0.77 & 15.92 & 16.27 & 17.62 & 18.86 & 19.72 & 0.25 & -0.02 & 0.00 \\
\hline D55 & Digit 4: Length, total, tip to wrist crease. & 14.63 & 19.17 & 16.74 & 0.80 & 14.79 & 15.37 & 16.75 & 18.07 & 18.63 & 0.94 & 0.01 & -0.11 \\
\hline D56 & Digit 5: Length, total, tip to wrist crease & 12.18 & 16.96 & 14.59 & 0.87 & 12.61 & 13.13 & 14.61 & 16.11 & 16.54 & 0.86 & -0.04 & -0.16 \\
\hline
\end{tabular}

\section{Procedure}

The procedures used to carry out the measurements were in accordance with the NASA-1024 guidelines. A rest of 10 min was given to subjects between measurement sessions. All measurements were taken daily in the afternoon between 13:00-15:00 $\mathrm{h}$. The subject's age was documented by the registered date of birth within their university registration files. Furthermore, subjects of the study were requested to provide written consent. Confidentiality of data was assured and all participants were informed that the data would only be used for the stated purpose of the survey. The field study was approved by the ethics review board of the Engineering College in February 2016. The board was established in 2014 at King Khalid University. Breadth, length and thickness were measured with an anthropometer and circumferences were measured with anthropometric tape. A training program was designed for those responsible for collecting the data. It was provided over two weeks, three times/week, twice a day for $60 \mathrm{~min}$ separated by $30 \mathrm{~min}$ of rest. The program included modules about anatomy, body landmarks and measurement 
instrument use and techniques. Five trials were carried out to evaluate each dimension and the overall mean value was noted.

\section{Statistical Analysis}

The collected data was comprehensively screened and cleaned. Initially, we collect data for 280 students. After missing values and outliers were removed, the final set of data consisted of 266 data measurements. The normality assumption for the 56 variables representing the measured hand dimensions was investigated in this study. For each anthropometric dimension, the following standard descriptive statistics were determined from directly measured dimensions: minimum, maximum, mean, Standard Deviation (SD), percentiles (1st, 5th, 50th, 95th and 99th), Shapiro-Wilk's normality test (SW) at $\mathrm{p}>0.05$, skewness $(\mathrm{Sk})$ and kurtosis $(\mathrm{Ku})$. In addition, Pearson's product moment correlation coefficient and its significance were used to find the correlations among the measured variables. Multivariate regression models were developed to estimate each hand dimension from the other hand dimensions. The statistical analysis was conducted using of computerized statistical analysis software (IBM SPSS Statistics for Windows 21). To indicate statistical significance, $5 \%$ and $1 \%$ levels of probability were used.

\section{Results}

\section{Sample Characteristics}

Table 1 presents the descriptive statistics of the 56 hand dimensions for Saudi university adult males at KKU. The table shows that hand dimensions were approximately normally distributed based on the values of SW, Sk and Ku.

\section{Bivariate Correlation}

The Pearson product-moment correlation coefficient was used to establish relationships among hand dimensions. The bivariate correlations reported in Table 2 indicate a significant positive correlation between most of the hand dimensions, which was consistent with Chandra et al. (2011). The white cells in Table 2 indicate a correlation is significant at 0.01 level (two-tailed), the shaded cells indicate a correlation significant at the 0.05 level (two-tailed) and a bordered cell indicates that the correlation is not significant.

\section{Constructing Regression Models}

In order to construct the regression models for each hand with the anthropometric dimension as a dependent variable and all other dimensions as independents, SPSS was set up to use stepwise linear regression models with a probability of $\mathrm{F}=0.05$, a removal probability of 0.10 and to include a constant in the equation option. Comprehensive regression modeling to estimate the hand length from other hand dimensions was conducted and the results are presented in Table 3 . Table 4 provides 56 multiple regression models for estimating each hand dimension in terms of hand length and hand breadth with $\mathrm{R}^{2}$.Furthermore, Table 5 provides 56 multiple regression equations in terms of hand length and fist circumference.

Thirteen regression models were determined using SPSS to define the relationship between hand length and the other 55 hand dimensions, as shown in Table 3. These models have a Variance Inflation Factor (VIF) of less than 10 or tolerance greater than 0.2 , which indicates that they are free from multicollinearity. The models are defined in terms of their parameters, standardized and un-standardized coefficients, significance and collinearity statistics (as tolerance and VIF). Column 1 in Table 3 lists the regression model number, which is the number of independent variables in the model. Column 2 lists the constant terms and the significant independent variables. For example, model 1 includes constant term $\mathrm{C}$ and one independent variable named D54, which corresponds to dimension 54 in the collected data set, while model 2 includes constant term $\mathrm{C}$ and two independent variables, D54 and D40. Columns 3 and 4 present the unstandardized coefficients of the model in terms of B and SE values, while Column 5 presents the standardized coefficients. The $\mathrm{B}$ values represent the regression coefficients and the $\mathrm{SE}$ values represent the standard errors of the coefficients. Standardized regression coefficients (Beta), $\mathrm{t}$ and the two-tailed probability of $\mathrm{t}$ (Sig.) are given in columns 6 and 7 . Columns 8 and 9 list the tolerance for the variables (Tol.) and VIF of collinearity while Column 10 gives the models' coefficient of determination $\left(\mathrm{R}^{2}\right)$.

Table 3 indicates that the $\mathrm{R}^{2}$ values for the developed models range from 0.881 to 0.962 and all models are adequate. Model 1, which is calculated as Hand length $=$ $1.31+0.94 \times$ "total tip to wrist crease" is estimated from un-standardized coefficients in Column 3. The model estimated from standardized coefficients in Column 5 is calculated as Hand length $=0.94 \times$ "total tip to wrist crease." The collinearity is measured in terms of Tol and VIF values. For this model, Tol $>0.2$ and VIF $<10$, so the model is free from multicollinearity. We note that the $\mathrm{R}^{2}$ value increases from 0.881 to 0.962 for the models with 1 to 13 independent variables. The maximum $R^{2}$ value is achieved by the model with 13 independent variables. The results listed in Table 4 and 5 show that the prediction of hand dimensions from hand length and breadth was better than predicting from hand length and fist circumference based on comparing the values of $\mathrm{R}^{2}$. 


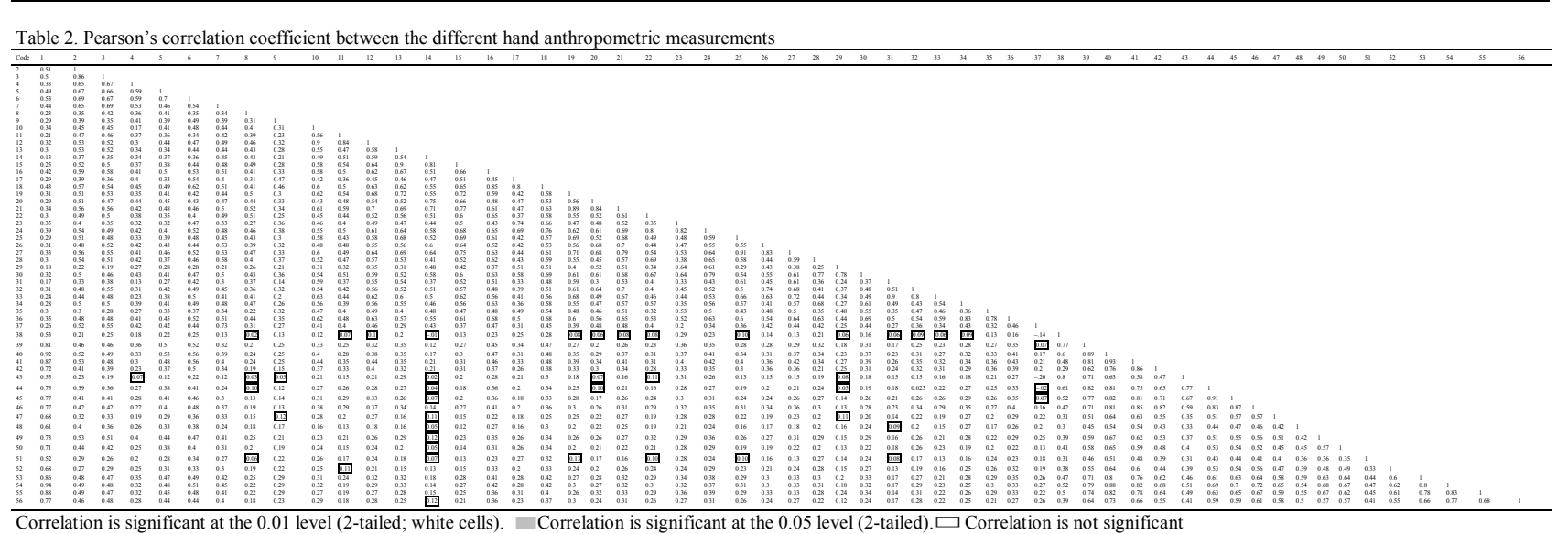

Table 3. Coefficients for hand length regression models

\begin{tabular}{|c|c|c|c|c|c|c|c|c|c|}
\hline & \multirow[b]{2}{*}{ Model } & \multicolumn{3}{|c|}{ Unst. Co. St. Co. } & \multirow[b]{2}{*}{$t$} & \multirow[b]{2}{*}{ Sig. } & \multicolumn{2}{|c|}{ Collinearity } & \multirow[b]{2}{*}{$R^{2}$} \\
\hline & & B & SE & Beta & & & Tol & VIF & \\
\hline \multirow[t]{2}{*}{$\overline{1}$} & $\mathrm{C}$ & 1.31 & 0.37 & & 3.49 & 0.00 & & & 0.881 \\
\hline & D54 & 0.94 & 0.02 & 0.94 & 44.23 & 0.00 & 1.00 & 1.00 & \\
\hline \multirow[t]{3}{*}{2} & $\mathrm{C}$ & 0.57 & 0.30 & & 1.87 & 0.06 & & & 0.925 \\
\hline & D54 & 0.56 & 0.04 & 0.56 & 15.92 & 0.00 & 0.23 & 4.30 & \\
\hline & D40 & 0.43 & 0.03 & 0.44 & 12.44 & 0.00 & 0.23 & 4.30 & \\
\hline \multirow[t]{4}{*}{3} & $\mathrm{C}$ & 0.35 & 0.27 & & 1.27 & 0.20 & & & 0.940 \\
\hline & D54 & 0.45 & 0.03 & 0.44 & 13.01 & 0.00 & 0.19 & 5.13 & \\
\hline & D40 & 0.33 & 0.03 & 0.34 & 10.20 & 0.00 & 0.20 & 4.90 & \\
\hline & D55 & 0.23 & 0.03 & 0.24 & 8.17 & 0.00 & 0.27 & 3.65 & \\
\hline \multirow[t]{5}{*}{4} & C & 0.29 & 0.25 & & 1.16 & 0.25 & & & 0.949 \\
\hline & D54 & 0.39 & 0.03 & 0.39 & 12.12 & 0.00 & 0.18 & 5.43 & \\
\hline & D40 & 0.28 & 0.03 & 0.28 & 8.91 & 0.00 & 0.19 & 5.25 & \\
\hline & D55 & 0.18 & 0.03 & 0.19 & 6.83 & 0.00 & 0.26 & 3.90 & \\
\hline & D53 & 0.16 & 0.02 & 0.18 & 6.83 & 0.00 & 0.29 & 3.39 & \\
\hline \multirow[t]{6}{*}{5} & $\mathrm{C}$ & 0.35 & 0.25 & & 1.43 & 0.15 & & & 0.952 \\
\hline & D54 & 0.40 & 0.03 & 0.40 & 12.62 & 0.00 & 0.18 & 5.44 & \\
\hline & D40 & 0.19 & 0.04 & 0.19 & 5.01 & 0.00 & 0.12 & 8.11 & \\
\hline & D55 & 0.18 & 0.03 & 0.19 & 7.11 & 0.00 & 0.26 & 3.90 & \\
\hline & D53 & 0.17 & 0.02 & 0.18 & 7.29 & 0.00 & 0.29 & 3.41 & \\
\hline & D45 & 0.13 & 0.03 & 0.10 & 3.97 & 0.00 & 0.32 & 3.17 & \\
\hline \multirow[t]{7}{*}{6} & $\mathrm{C}$ & 0.52 & 0.25 & & 2.10 & 0.04 & & & 0.954 \\
\hline & D54 & 0.39 & 0.03 & 0.39 & 12.62 & 0.00 & 0.18 & 5.46 & \\
\hline & D40 & 0.18 & 0.04 & 0.18 & 4.73 & 0.00 & 0.12 & 8.20 & \\
\hline & D55 & 0.18 & 0.03 & 0.18 & 6.88 & 0.00 & 0.25 & 3.94 & \\
\hline & D53 & 0.16 & 0.02 & 0.17 & 6.96 & 0.00 & 0.29 & 3.47 & \\
\hline & D45 & 0.12 & 0.03 & 0.09 & 3.84 & 0.00 & 0.31 & 3.18 & \\
\hline & D52 & 0.05 & 0.01 & 0.06 & 3.18 & 0.00 & 0.55 & 1.80 & \\
\hline \multirow[t]{8}{*}{7} & $\mathrm{C}$ & 0.46 & 0.24 & & 1.90 & 0.06 & & & 0.956 \\
\hline & D54 & 0.39 & 0.03 & 0.39 & 12.70 & 0.00 & 0.18 & 5.47 & \\
\hline & D40 & 0.18 & 0.04 & 0.18 & 4.89 & 0.00 & 0.12 & 8.20 & \\
\hline & D55 & 0.17 & 0.03 & 0.17 & 6.62 & 0.00 & 0.25 & 3.99 & \\
\hline & D53 & 0.14 & 0.02 & 0.15 & 6.09 & 0.00 & 0.27 & 3.68 & \\
\hline & D45 & 0.11 & 0.03 & 0.08 & 3.61 & 0.00 & 0.31 & 3.20 & \\
\hline & D52 & 0.05 & 0.01 & 0.06 & 3.27 & 0.00 & 0.55 & 1.80 & \\
\hline & D48 & 0.09 & 0.03 & 0.05 & 3.23 & 0.00 & 0.63 & 1.60 & \\
\hline \multirow[t]{9}{*}{8} & C & 0.48 & 0.24 & & 2.01 & 0.05 & & & 0.958 \\
\hline & D54 & 0.37 & 0.03 & 0.37 & 12.26 & 0.00 & 0.18 & 5.61 & \\
\hline & D40 & 0.17 & 0.04 & 0.18 & 4.77 & 0.00 & 0.12 & 8.24 & \\
\hline & D55 & 0.15 & 0.03 & 0.16 & 6.13 & 0.00 & 0.24 & 4.10 & \\
\hline & D53 & 0.14 & 0.02 & 0.15 & 5.88 & 0.00 & 0.27 & 3.71 & \\
\hline & D45 & 0.11 & 0.03 & 0.08 & 3.57 & 0.00 & 0.31 & 3.21 & \\
\hline & D52 & 0.05 & 0.01 & 0.06 & 3.32 & 0.00 & 0.55 & 1.80 & \\
\hline & D48 & 0.09 & 0.03 & 0.05 & 3.32 & 0.00 & 0.63 & 1.60 & \\
\hline & D49 & 0.09 & 0.03 & 0.06 & 3.16 & 0.00 & 0.49 & 2.05 & \\
\hline
\end{tabular}


Mohamed A.A. Mansour et al. / American Journal of Engineering and Applied Sciences 2016, 9 (4): 877.888 DOI: 10.3844/ajeassp.2016.877.888

\begin{tabular}{|c|c|c|c|c|c|c|c|c|c|}
\hline \multirow[t]{10}{*}{9} & $\mathrm{C}$ & 0.91 & 0.28 & & 3.27 & 0.00 & & & \multirow[t]{10}{*}{0.959} \\
\hline & D54 & 0.37 & 0.03 & 0.37 & 12.18 & 0.00 & 0.18 & 5.64 & \\
\hline & D40 & 0.19 & 0.04 & 0.19 & 5.27 & 0.00 & 0.12 & 8.49 & \\
\hline & D55 & 0.16 & 0.02 & 0.16 & 6.35 & 0.00 & 0.24 & 4.11 & \\
\hline & D53 & 0.14 & 0.02 & 0.15 & 6.00 & 0.00 & 0.27 & 3.71 & \\
\hline & D45 & 0.10 & 0.03 & 0.08 & 3.31 & 0.00 & 0.31 & 3.24 & \\
\hline & D52 & 0.05 & 0.01 & 0.06 & 3.48 & 0.00 & 0.55 & 1.81 & \\
\hline & D48 & 0.09 & 0.03 & 0.06 & 3.49 & 0.00 & 0.63 & 1.60 & \\
\hline & D49 & 0.10 & 0.03 & 0.06 & 3.35 & 0.00 & 0.49 & 2.06 & \\
\hline & D30 & -0.13 & 0.05 & -0.04 & -2.91 & 0.00 & 0.84 & 1.19 & \\
\hline \multirow[t]{11}{*}{10} & $\mathrm{C}$ & 0.72 & 0.29 & & 2.51 & 0.01 & & & \multirow[t]{11}{*}{0.960} \\
\hline & D54 & 0.35 & 0.03 & 0.35 & 11.58 & 0.00 & 0.17 & 5.87 & \\
\hline & D40 & 0.20 & 0.04 & 0.21 & 5.65 & 0.00 & 0.11 & 8.73 & \\
\hline & D55 & 0.16 & 0.02 & 0.17 & 6.54 & 0.00 & 0.24 & 4.12 & \\
\hline & D53 & 0.13 & 0.02 & 0.14 & 5.82 & 0.00 & 0.27 & 3.74 & \\
\hline & D45 & 0.11 & 0.03 & 0.08 & 3.55 & 0.00 & 0.31 & 3.27 & \\
\hline & D52 & 0.05 & 0.01 & 0.06 & 3.40 & 0.00 & 0.55 & 1.81 & \\
\hline & D48 & 0.09 & 0.03 & 0.05 & 3.37 & 0.00 & 0.62 & 1.61 & \\
\hline & D49 & 0.09 & 0.03 & 0.06 & 3.11 & 0.00 & 0.48 & 2.08 & \\
\hline & D30 & -0.18 & 0.05 & -0.06 & -3.67 & 0.00 & 0.70 & 1.43 & \\
\hline & D37 & 0.09 & 0.04 & 0.04 & 2.42 & 0.02 & 0.72 & 1.40 & \\
\hline \multirow[t]{12}{*}{11} & $\mathrm{C}$ & 0.69 & 0.28 & & 2.44 & 0.02 & & & \multirow[t]{12}{*}{0.961} \\
\hline & D54 & 0.34 & 0.03 & 0.34 & 11.05 & 0.00 & 0.16 & 6.06 & \\
\hline & D40 & 0.20 & 0.04 & 0.21 & 5.70 & 0.00 & 0.11 & 8.73 & \\
\hline & D55 & 0.16 & 0.02 & 0.17 & 6.57 & 0.00 & 0.24 & 4.12 & \\
\hline & D53 & 0.12 & 0.02 & 0.13 & 5.45 & 0.00 & 0.26 & 3.82 & \\
\hline & D45 & 0.11 & 0.03 & 0.08 & 3.51 & 0.00 & 0.31 & 3.27 & \\
\hline & D52 & 0.04 & 0.01 & 0.05 & 3.25 & 0.00 & 0.55 & 1.82 & \\
\hline & D48 & 0.09 & 0.03 & 0.05 & 3.24 & 0.00 & 0.62 & 1.61 & \\
\hline & D49 & 0.08 & 0.03 & 0.05 & 2.72 & 0.01 & 0.47 & 2.13 & \\
\hline & D30 & -0.18 & 0.05 & -0.05 & -3.69 & 0.00 & 0.70 & 1.43 & \\
\hline & D37 & 0.09 & 0.04 & 0.04 & 2.65 & 0.01 & 0.71 & 1.41 & \\
\hline & D50 & 0.08 & 0.03 & 0.05 & 2.57 & 0.01 & 0.49 & 2.03 & \\
\hline \multirow[t]{13}{*}{12} & $\mathrm{C}$ & 0.75 & 0.28 & & 2.65 & 0.01 & & & \multirow[t]{13}{*}{0.961} \\
\hline & D54 & 0.33 & 0.03 & 0.33 & 10.83 & 0.00 & 0.16 & 6.13 & \\
\hline & D40 & 0.22 & 0.04 & 0.22 & 5.97 & 0.00 & 0.11 & 8.92 & \\
\hline & D55 & 0.16 & 0.02 & 0.17 & 6.72 & 0.00 & 0.24 & 4.13 & \\
\hline & D53 & 0.12 & 0.02 & 0.13 & 5.44 & 0.00 & 0.26 & 3.82 & \\
\hline & D45 & 0.11 & 0.03 & 0.08 & 3.64 & 0.00 & 0.30 & 3.28 & \\
\hline & D52 & 0.04 & 0.01 & 0.05 & 2.73 & 0.01 & 0.52 & 1.91 & \\
\hline & D48 & 0.09 & 0.03 & 0.05 & 3.46 & 0.00 & 0.61 & 1.63 & \\
\hline & D49 & 0.09 & 0.03 & 0.06 & 3.12 & 0.00 & 0.45 & 2.23 & \\
\hline & D30 & -0.16 & 0.05 & -0.05 & -3.12 & 0.00 & 0.66 & 1.52 & \\
\hline & D37 & 0.13 & 0.04 & 0.05 & 3.29 & 0.00 & 0.59 & 1.71 & \\
\hline & D50 & 0.09 & 0.03 & 0.05 & 2.89 & 0.00 & 0.48 & 2.09 & \\
\hline & D02 & -0.09 & 0.04 & -0.04 & -2.07 & 0.04 & 0.44 & 2.26 & \\
\hline \multirow[t]{14}{*}{13} & $\mathrm{C}$ & 0.66 & 0.28 & & 2.32 & 0.02 & & & \multirow[t]{14}{*}{0.962} \\
\hline & D54 & 0.33 & 0.03 & 0.33 & 10.83 & 0.00 & 0.16 & 6.14 & \\
\hline & D40 & 0.22 & 0.04 & 0.22 & 6.11 & 0.00 & 0.11 & 8.95 & \\
\hline & D55 & 0.16 & 0.02 & 0.17 & 6.70 & 0.00 & 0.24 & 4.14 & \\
\hline & D53 & 0.12 & 0.02 & 0.13 & 5.32 & 0.00 & 0.26 & 3.84 & \\
\hline & D45 & 0.11 & 0.03 & 0.08 & 3.57 & 0.00 & 0.30 & 3.28 & \\
\hline & D52 & 0.04 & 0.01 & 0.05 & 2.72 & 0.01 & 0.52 & 1.91 & \\
\hline & D48 & 0.10 & 0.03 & 0.06 & 3.65 & 0.00 & 0.61 & 1.64 & \\
\hline & D49 & 0.09 & 0.03 & 0.06 & 3.06 & 0.00 & 0.45 & 2.24 & \\
\hline & D30 & -0.26 & 0.07 & -0.08 & -3.63 & 0.00 & 0.33 & 3.08 & \\
\hline & D37 & 0.14 & 0.04 & 0.06 & 3.53 & 0.00 & 0.58 & 1.73 & \\
\hline & D50 & 0.08 & 0.03 & 0.05 & 2.88 & 0.00 & 0.48 & 2.09 & \\
\hline & D02 & -0.10 & 0.04 & -0.05 & -2.46 & 0.01 & 0.42 & 2.37 & \\
\hline & D24 & 0.14 & 0.07 & 0.04 & 2.00 & 0.05 & 0.33 & 3.03 & \\
\hline
\end{tabular}


Table 4. Multiple regression equations in terms of hand length and hand breadth

\begin{tabular}{|c|c|c|c|c|c|c|c|c|c|c|c|}
\hline \multirow[b]{2}{*}{ Dim. } & \multicolumn{3}{|c|}{ Model coefficients } & \multicolumn{3}{|c|}{ Model accuracy } & \multicolumn{3}{|c|}{ Model coefficients } & \multicolumn{2}{|c|}{ Model accuracy } \\
\hline & Constant & $\mathrm{D}_{1}$ & $\mathrm{D}_{2}$ & $R^{2}$ & SE & Dim. & Constant & $\mathrm{D}_{1}$ & $\mathrm{D}_{2}$ & $R^{2}$ & SE \\
\hline D1 & 0.000 & 1.000 & 0.0000 & 1.000 & 0.000 & D29 & 0.955 & 0.012 & 0.052 & 0.057 & 0.098 \\
\hline D2 & 0.000 & 0.000 & 1.000 & 1.000 & 0.000 & D30 & 2.297 & 0.026 & 0.304 & 0.254 & 0.201 \\
\hline D3 & 3.879 & 0.080 & 1.737 & 0.737 & 0.381 & D31 & 0.682 & -0.001 & 0.083 & 0.112 & 0.080 \\
\hline D4 & 5.311 & 0.003 & 2.077 & 0.418 & 0.854 & D32 & 0.140 & 0.010 & 0.105 & 0.238 & 0.073 \\
\hline D5 & 3.871 & 0.274 & 1.789 & 0.482 & 0.781 & D33 & 1.567 & 0.005 & 0.287 & 0.197 & 0.205 \\
\hline D6 & 3.986 & 0.362 & 1.865 & 0.513 & 0.807 & D34 & 0.453 & 0.004 & 0.121 & 0.253 & 0.075 \\
\hline D7 & 4.272 & 0.119 & 1.112 & 0.441 & 0.497 & D35 & 0.653 & 0.021 & 0.046 & 0.119 & 0.770 \\
\hline D8 & 1.285 & 0.016 & 0.156 & 0.127 & 0.161 & D36 & 1.596 & 0.042 & 0.276 & 0.249 & 0.201 \\
\hline D9 & 1.424 & 0.056 & 0.353 & 0.163 & 0.339 & D37 & 2.177 & -0.003 & 0.481 & 0.268 & 0.274 \\
\hline D10 & 0.528 & 0.023 & 0.125 & 0.217 & 0.104 & D38 & -1.046 & 0.619 & -0.190 & 0.290 & 0.707 \\
\hline D11 & 0.591 & -0.005 & 0.150 & 0.233 & 0.094 & D39 & 0.117 & 0.837 & 0.165 & 0.662 & 0.487 \\
\hline D12 & 1.769 & 0.026 & 0.437 & 0.286 & 0.285 & D40 & 0.127 & 0.910 & 0.151 & 0.856 & 0.302 \\
\hline D13 & 0.350 & 0.006 & 0.140 & 0.281 & 0.082 & D41 & -0.830 & 0.842 & 0.270 & 0.765 & 0.392 \\
\hline D14 & 0.605 & -0.009 & 0.102 & 0.146 & 0.078 & D42 & -1.337 & 0.736 & 0.247 & 0.517 & 0.580 \\
\hline D15 & 1.607 & -0.007 & 0.386 & 0.270 & 0.216 & D43 & -1.292 & 0.441 & -0.118 & 0.309 & 0.485 \\
\hline D16 & 0.412 & 0.019 & 0.138 & 0.367 & 0.075 & D44 & -0.592 & 0.571 & 0.024 & 0.559 & 0.399 \\
\hline D17 & 0.722 & 0.014 & 0.084 & 0.166 & 0.080 & D45 & -0.589 & 0.562 & 0.024 & 0.597 & 0.365 \\
\hline D18 & 1.491 & 0.065 & 0.358 & 0.354 & 0.211 & D46 & -1.910 & 0.564 & 0.067 & 0.290 & 0.376 \\
\hline D19 & 0.499 & 0.007 & 0.118 & 0.266 & 0.073 & D47 & 1.571 & 0.468 & -0.049 & 0.460 & 0.335 \\
\hline D20 & 0.235 & 0.005 & 0.127 & .258 & 0.079 & D48 & -0.275 & 0.325 & 0.167 & 0.383 & 0.364 \\
\hline D21 & 1.176 & 0.023 & 0.378 & 0.321 & 0.205 & D49 & -1.371 & 0.383 & 0.299 & 0.560 & 0.321 \\
\hline D22 & 0.747 & 0.009 & 0.120 & 0.242 & 0.080 & D50 & -0.809 & 0.397 & 0.134 & 0.511 & 0.328 \\
\hline D23 & 0.543 & 0.026 & 0.085 & 0.191 & 0.090 & D51 & 0.580 & 0.257 & 0.035 & 0.267 & 0.342 \\
\hline D24 & 2.138 & 0.049 & 0.321 & 0.305 & 0.204 & D52 & -3.007 & 0.902 & -0.282 & 0.468 & 0.701 \\
\hline D25 & 0.400 & 0.004 & 0.124 & 0.264 & 0.074 & D53 & -0.499 & 0.898 & 0.134 & 0.750 & 0.418 \\
\hline D26 & .177 & 0.010 & 0.116 & 0.240 & 0.080 & D54 & 0.725 & 0.828 & 0.039 & 0.881 & 0.267 \\
\hline D27 & 1.143 & 0.017 & 0.362 & 0.317 & 0.195 & D55 & 0.005 & 0.880 & 0.131 & 0.784 & 0.372 \\
\hline D28 & 0.550 & 0.004 & 0.138 & 0.295 & 0.76 & D56 & -1.723 & 0.881 & 0.373 & 0.606 & 0.547 \\
\hline
\end{tabular}

Table 5. Multiple regression equations in terms of hand length and fist circumference

\begin{tabular}{|c|c|c|c|c|c|c|c|c|c|c|c|}
\hline \multirow[b]{2}{*}{ Dim. } & \multicolumn{3}{|c|}{ Model coefficients } & \multicolumn{2}{|c|}{ Model accuracy } & \multirow[b]{2}{*}{ Dim. } & \multicolumn{3}{|c|}{ Model coefficients } & \multicolumn{2}{|c|}{ Model accuracy } \\
\hline & Constant & $\mathrm{D}_{1}$ & $\mathrm{D}_{6}$ & $R^{2}$ & SE & & Constant & $\mathrm{D}_{1}$ & $\mathrm{D}_{6}$ & $R^{2}$ & SE \\
\hline$\overline{\mathrm{D} 1}$ & 0.000 & 1.000 & 0.000 & 1.000 & 0.000 & D29 & 0.897 & 0.006 & 0.023 & 0.082 & 0.097 \\
\hline D2 & 1.742 & 0.091 & 0.164 & 0.500 & 0.246 & D30 & 2.480 & 0.029 & 0.085 & 0.230 & 0.205 \\
\hline D3 & 6.231 & 0.189 & 0.365 & 0.479 & 0.537 & D31 & 0.611 & 0.009 & 0.035 & 0.185 & 0.077 \\
\hline D4 & 6.788 & 0.035 & 0.561 & 0.351 & 0.903 & D32 & 0.173 & 0.009 & 0.032 & 0.240 & 0.074 \\
\hline D5 & 4.195 & 0.232 & 0.571 & 0.506 & 0.763 & D33 & 0.501 & 0.011 & 0.103 & 0.250 & 0.199 \\
\hline D6 & 0.000 & 0.000 & 1.000 & 1.000 & 0.000 & D34 & 0.511 & 0.003 & 0.035 & 0.238 & 0.076 \\
\hline D7 & 5.649 & 0.179 & 0.179 & 0.245 & 0.321 & D35 & 0.600 & 0.016 & 0.021 & 0.150 & 0.076 \\
\hline D8 & 1.335 & 0.013 & 0.048 & 0.127 & 0.161 & D36 & 1.592 & 0.031 & 0.093 & 0.277 & 0.272 \\
\hline D9 & 1.094 & 0.018 & 0.150 & 0.239 & 0.323 & D37 & 2.641 & 0.013 & 0.118 & 0.197 & 0.287 \\
\hline D10 & 0.525 & 0.018 & 0.042 & 0.239 & 0.103 & D38 & -1.346 & 0.604 & -0.036 & 0.287 & 0.708 \\
\hline D11 & 0.818 & 0.006 & 0.029 & 0.118 & 0.100 & D39 & -0.288 & 0.801 & 0.093 & 0.671 & 0.481 \\
\hline D12 & 2.169 & 0.039 & 0.110 & 0.227 & 0.269 & D40 & -0.062 & 0.891 & 0.068 & 0.860 & 0.298 \\
\hline D13 & 0.506 & 0.012 & 0.033 & 0.202 & 0.086 & D41 & -0.901 & 0.827 & 0.096 & 0.769 & 0.389 \\
\hline D14 & 0.655 & -0.009 & 0.030 & 0.134 & 0.079 & D42 & -2.089 & 0.675 & 0.120 & 0.534 & 0.570 \\
\hline D15 & 2.001 & 0.007 & 0.093 & 0.192 & 0.228 & D43 & -1.206 & 0.452 & -0.048 & 0.311 & 0.484 \\
\hline D16 & 0.533 & 0.023 & 0.035 & 0.308 & 0.079 & D44 & -0.640 & 0.567 & 0.013 & 0.559 & 0.399 \\
\hline D17 & 0.583 & 0.001 & 0.041 & 0.249 & 0.074 & D45 & -0.816 & 0.544 & 0.035 & 0.600 & 0.364 \\
\hline D18 & 1.456 & 0.049 & 0.124 & 0.401 & 0.203 & D46 & -2.204 & 0.539 & 0.050 & 0.596 & 0.373 \\
\hline D19 & 0.641 & 0.013 & 0.026 & 0.186 & 0.077 & D47 & -1.784 & 0.394 & 0.003 & 0.459 & 0.336 \\
\hline D20 & 0.369 & 0.011 & 0.030 & 0.191 & 0.083 & D48 & 0.013 & 0.340 & 0.030 & 0.376 & 0.366 \\
\hline D21 & 1.627 & 0.042 & 0.085 & 0.227 & 0.219 & D49 & -0.800 & 0.414 & 0.047 & 0.535 & 0.330 \\
\hline D22 & 0.898 & 0.016 & 0.026 & 0.169 & 0.085 & D50 & -0.469 & 0.418 & 0.013 & 0.504 & 0.330 \\
\hline D23 & 0.489 & 0.019 & 0.034 & 0.236 & 0.087 & D51 & 0.372 & 0.240 & 0.031 & 0.272 & 0.341 \\
\hline D24 & 2.318 & 0.051 & 0.091 & 0.285 & 0.207 & D52 & -3.667 & 0.864 & -0.033 & 0.462 & 0.705 \\
\hline D25 & 0.484 & 0.006 & 0.034 & 0.288 & 0.077 & D53 & -0.382 & 0.902 & 0.034 & 0.750 & 0.418 \\
\hline D26 & 0.274 & 0.013 & 0.030 & 0.199 & 0.082 & D54 & 0.697 & 0.924 & 0.016 & 0.881 & 0.267 \\
\hline D27 & 1.404 & 0.022 & 0.097 & 0.270 & 0.202 & D55 & 0.385 & 0.903 & 0.008 & 0.782 & 0.374 \\
\hline D28 & 0.695 & 0.010 & 0.033 & 0.216 & 0.081 & D56 & -1.174 & 0.843 & 0.028 & 0.600 & 0.550 \\
\hline
\end{tabular}




\section{Discussion}

The descriptive statistics given in this study can be considered a basis for developing a comprehensive anthropometric database. Additionally, for the values of $\mathrm{SW}$, Sk and $\mathrm{Ku}, 98.23 \%$ of the collecting readings of the 56-dimensional variable fit to a normal curve because of the data cleaning procedure adopted for the data set.

All correlation coefficients between the 56 hand dimensions were positively related except for the relationship between "Digit 1: Height, perpendicular to wrist crease" and "Digit 2: Distal inter-phalangeal joint depth," which is negative, but near to zero. Further, $93.89 \%$ of the coefficients are significant at a level of $1 \%$. In addition, $3.25 \%$ of coefficients are significant at the level of $5 \%$ and all the remaining coefficients $(2.86 \%)$ were found to have no significance.

The results of the current study show that $29.80 \%$ of the correlation coefficients $(0.50<\mathrm{r} \leq 1.00)$ show a strong relationship between hand dimensions, $2.05 \%$ of correlation coefficients $(0.30 \leq \mathrm{r}<0.50)$ are moderately correlated and $68.15 \%$ of correlation coefficients $(0.00 \leq \mathrm{r}<0.30)$ are poorly correlated. In addition, the mean correlation coefficient is 0.40 , indicating that there is a moderately significant correlation between hand dimensions.

The average $\mathrm{R}^{2}$ of the prediction models is 0.948 , which indicates a good linear relationship between hand dimensions. Thus, the designers of man-machine systems and hand tools used by the age range in this study can use the statistics and prediction equations presented in this work. The prediction equations illustrated in Tables 4 and 5 could be deployed for predicting 56 hand dimensions with $95 \%$ confidence by evaluating hand breadth, fist circumference and hand length. The average $\mathrm{R}^{2}$ for estimating all hand dimensions from hand length and hand breadth is 0.396 , in contrast to that of estimating all hand dimensions from hand length and fist circumference, which is 0.383 .

\section{Conclusion}

Fifty-six hand measurements of Saudi Arabian adult males, aged 20-26 years, who were enrolled in engineering programs at KKU were collected and summarized. The data was then analyzed using correlation and multiple regression. These data will be of great value for designing new products, hand tools, workstations, gloves (Hsiao et al., 2015), personal protective equipment for engineering students and other practical applications, especially user-friendly manmachine systems. This is the first ever large-scale hand anthropometric measurement of engineering students in Saudi Arabia and it will be a considerable contribution to the anthropometric data of Saudi Arabia. In addition, this study provides a bivariate correlation analysis using Pearson's correlation coefficient to measure the relationship between the 56 hand dimensions at 0.01 and 0.05 significance levels. The analysis shows positive significant correlations among all dimensions except for between "Digit 1: Height, perpendicular to wrist crease" and "Digit 2: Distal inter-phalangeal joint depth." Furthermore, the study provides multivariate regression models for estimating any hand dimension from all other hand dimensions and 13 regression models for estimating hand length.

A natural expansion of this work is to investigate the interaction between the collected hand measurements and physical abilities of the hand such as gripping strength. A larger sample size in terms of gender, age range, region and other occupational groups should be investigated to obtain proper anthropometric data for the ergonomic design of practical man-machine systems in Saudi Arabia. In addition, we could expand this work by conducting a survey to compare the hand anthropometric characteristics of Saudi people with other populations or use this data to create biomechanical hand models.

\section{Acknowledgement}

The author is very grateful to the Department of Industrial Engineering, College of Engineering, King Khalid University, Kingdom of Saudi Arabia for providing all facilities to carry out the field study. Finally, the author would like to thank the reviewers for their helpful and constructive comments that helped improving the manuscript.

\section{Ethics}

The field study was approved by the review board established in 2014 at the College of Engineering at King Khalid University that responsible for human measurement and in accordance with the Helsinki Declaration of 1975, as revised in 2000 and 2008.

\section{References}

Abeysekera, J., 1988. A comparative study of body size variability between people in industrialized countries and industrially developing countries, its impact on the use of imported goods. Applied Ergonomics, 19: 338.

DOI: $10.1016 / 0003-6870(88) 90102-0$

Abeysekera, J.D. and H. Shahnavaz, 1989. Body size variability between people in developed and developing countries and its impact on the use of imported goods. Int. J. Industrial Ergonomics, 4: 139-149. DOI: 10.1016/0169-8141(89)90040-1

Abeysekera, J.D.A. and H. Shahnavaz, 1988. Body size data of Sri Lankan workers and comparison with other populations in the world: Its impact on the use of imported goods. J. National Science Council Sri Lanka, 16: 67-86. 
Aghazadeh, F. and A. Mital, 1987. Injuries due to handtools: Results of a questionnaire. Applied Ergonomics, 18: 273-278.

DOI: 10.1016/0003-6870(87)90134-7

Ahn, S.H., S. Kwon, S. Bahn, M.H. Yun and W. Yu, 2016. Effects of grip curvature and hand anthropometry for the unimanual operation of touchscreen handheld devices. Human Factors Ergonomics Manufacturing Service Industries, 26: 367-380. DOI: $10.1002 / \mathrm{hfm} .20662$

Al-Hazzaa, H.M., 1990. Anthropometric measurements of Saudi boys aged 6-14 years. Annals Human Biology, 17: 33-40.

DOI: $10.1080 / 03014469000000762$

Ali, I. and N. Arslan, 2009. Estimated anthropometric measurements of Turkish adults and effects of age and geographical regions. Int. J. Industrial Ergonomics, 39: 860-865.

DOI: 10.1016/j.ergon.2009.02.007

Alrashdan, A., L. Alsudairi and A. Alqaddoumi, 2014. Anthropometry of Saudi Arabian female college students. Proceedings of the Industrial and Systems Engineering Research Conference, Riyadh, Saudi Arabia, pp: 4075- 4083.

Annett, M., 1970. A classification of hand preference by association analysis. British J. Psychology, 61: 303321. DOI: 10.1111/j.2044-8295.1970.tb01248.x

Botha, W. and R. Bridger, 1998. Anthropometric variability, equipment usability and musculoskeletal pain in a group of nurses in the Western Cape. Applied Ergonomics, 29: 481-490.

DOI: 10.1016/s0003-6870(97)00081-1

Buchholz, B. and T. Armstrong, 1991. An ellipsoidal representation of human hand anthropometry. J. Human Factors Ergonomics Society, 33: 429-441. DOI: $10.1177 / 001872089103300405$

Buchholz, B., T.J. Armstrong and S.A. Goldstein, 1992. Anthropometric data for describing the kinematics of the human hand. Ergonomics, 35: 261-273. DOI: $10.1080 / 00140139208967812$

Bures, M., T. Gorner and B. Sediva, 2015. Hand anthropometry of Czech population. Proceedings of the IEEE International Conference on Industrial Engineering and Engineering Management, Dec. 6-9, IEEE Xplore press, Czech Republic. DOI: $10.1109 /$ ieem.2015.7385814

Cakit, E., B. Durgun, O. Cetik and O. Yoldas, 2012. A survey of hand anthropometry and biomechanical measurements of dentistry students in Turkey. Human Factors Ergonomics Manufacturing Service Industries Hum, 24: 739-753. DOI: $10.1002 / \mathrm{hfm} .20401$

Chandra, A., P. Chandna and S. Deswal, 2011. Hand anthropometric survey of male industrial workers of Haryana state (India). Int. J. Industrial Systems Eng., 9: 163-182. DOI: 10.1504/IJISE.2011.042833
Claudon, L., 2000. Ergonomics hand tools design: Interview of users. Ergonomics and safety for global business quality and productivity. Proceedings of the 2nd International Conference ERGON-AXIA 2000, Central Institute for Labour Protection, Warsaw, Poland.

Courtney, A.J., 1984. Hand anthropometry of Hong Kong Chinese females compared to other ethnic groups. Ergonomics, 27: 1169-1180. DOI: $10.1080 / 00140138408963598$

Davies, B.T., A. Abada, K. Benson, A. Courtney and I. Minto, 1980a. Female hand dimensions and guarding of machines. Ergonomics, 23: 79-84. DOI: $10.1080 / 00140138008924720$

Davies, B.T., A. Abada, K. Benson, A. Courtney and I. Minto, 1980b. A comparison of hand anthropometry of females in three ethnic groups. Ergonomics, 23: 179-182. DOI: $10.1080 / 00140138008924731$

Dianat, I., M.A. Karimi, A.A. Hashemi and S. Bahrampour, 2013. Classroom furniture and anthropometric characteristics of Iranian high school students: Proposed dimensions based on anthropometric data. Applied Ergonomics, 44: 101-108. DOI: 10.1016/j.apergo.2012.05.004

Ermacova, S., T. Podstavkina and A. Strokina, 1985. Anthropometric Atlas, Recommendation on Methods. Amerind Publishing Company, New Delhi, India.

García-Cáceres, R.G., S. Felknor, J.E. Córdoba, J.P. Caballero and L.H. Barrero, 2012. Hand anthropometry of the Colombian floriculture workers of the Bogota plateau. Int. J. Industrial Ergonomics, 42: 183-198.

DOI: $10.1016 /$ j.ergon.2011.12.002

Garrett, J., 1970. Anthropometry of the air force female hand. Aerospace Medical Research Laboratory, Aerospace Medical Division, Air Force Systems Command, Wright-Patterson AFB, OH 45433, USA.

Greiner, T., 1991. Hand anthropometry of US Army personnel. United States Army Natick Research, Development and Engineering Center, Natick, Massachusetts 01760-5000, USA.

Hsiao, H., J. Whitestone, T. Kau and B. Hildreth, 2015. Firefighter hand anthropometry and structural glove sizing: A new perspective. Human Factors, 57: 1359-1377. DOI: $10.1177 / 0018720815594933$

Imrhan, S. and M.G. Contreras, 2005. Hand anthropometry in a sample of Mexicans in the US Mexico border region. Proceedings of the XIX Annual Occupational Ergonomics and Safety Conference, Las Vegas, USA, pp: 589-593.

Imrhan, S., M. Sarder and N. Mandahawi, 2006. Hand anthropometry in a sample of Bangladesh males. Proceedings of the IIE Annual Conference, IIE, Zarqa, Jordan, pp: 1-5. 
Imrhan, S.N., M. Sarder and N. Mandahawi, 2009. Hand anthropometry in Bangladeshis living in America and comparisons with other populations. Ergonomics, 52: 987-998.

DOI: $10.1080 / 00140130902792478$

Irwin, C.B. and R.G. Radwin, 2008. A new method for estimating hand internal loads from external force measurements. Ergonomics, 51: 156-167.

DOI: $10.1080 / 00140130701526408$

Ismaila, O.S., 2009. Anthropometric data of hand, foot and ear of university students in Nigeria. Leonardo J. Sciences, 15: 15-200.

Ismaila, S., A.I. Musa, S.B. Adejuyigbe and O.D. Akinyemi, 2013. Anthropometric design of furniture for use in tertiary institutions in Abeokuta, Southwestern Nigeria. Eng. Rev., 33: 179-192.

Jain, S., 2012. Importance of anthropometry for designing user-friendly devices: Mobile phones. J. Ergonomics, 2: 109.

DOI: $10.4172 / 2165-7556.1000109$

Kar, S., S. Ghosh, I. Manna, S. Banerjee and P. Dhara, 2003. An investigation of hand anthropometry of agricultural workers. J. Human Ecology, 14: 57-62.

Kember, P., L. Ainsworth and P. Brightman, 1981. A hand anthropometric survey of British workers. Ergonomics Laboratory, Cranfield Institute of Technology.

Lewis, W.G. and C. Narayan, 1993. Design and sizing of ergonomic handles for hand tools. Applied Ergonomics, 24: 351-356. DOI: 10.1016/0003-6870(93)90074-j

Malina, R. and P. Buschang, 1984. Anthropometric asymmetry in normal and mentally retarded males. Annals Human Biology, 11: 515-531. DOI: $10.1080 / 03014468400007431$

Mandahawi, N., S. Imrhan, S. Al-Shobaki and B. Sarder, 2008. Hand anthropometry survey for the Jordanian population. Int. J. Industrial Ergonomics, 38: 966976. DOI: 10.1016/j.ergon.2008.01.010

Meagher, S.W., 1987. Tool design for prevention of hand and wrist injuries. J. Hand Surgery, 12: 855857. DOI: $10.1016 / \mathrm{s} 0363-5023(87) 80248-4$

Meagher, S.W., 1989. Design of hand tools for control of cumulative trauma disorders. Applied Industrial Hygiene. DOI: 10.1080/08828032.1989.10389916.

Mirmohammadi, S.J., A.H. Mehrparvar, M. Mostaghaci, M.H. Davari and M. Bahaloo et al., 2016. Anthropometric hand dimensions in a population of Iranian male workers in 2012. Int. J. Occupational Safety Ergonomics, 22: 125-130.

DOI: $10.1080 / 10803548.2015 .1112108$
Mohammad, Y.A., 2005. Anthropometric characteristics of the hand based on laterality and sex among Jordanian. Int. J. Industrial Ergonomics, 35: 747-754.

DOI: $10.1016 /$ j.ergon.2004.11.005

Mokdad, M. and M. Al-Ansari, 2009. Anthropometrics for the design of Bahraini school furniture. Int. J. Industrial Ergonomics, 39: 728-735. DOI: $10.1016 /$ j.ergon.2009.02.006

Nag, A., P. Nag and H. Desai, 2003. Hand anthropometry of Indian women. Indian J. Medical Res., 117: 260-269.

NASA Reference Publication 1024, 1978. Anthropometric Source Book Volume III.

Norris, B. and J. Wilson, 1997. Designing safety into products making ergonomics evaluation a part of the design process. University of Nottingham, Nottingham, UK.

Noweir, M., A. Bafail and I. Jomoah, 2001. Anthropometric norms of Saudi population. Final product\#103/417, College of Engineering Research Center, King Abdulazziz University, Saudi Arabia.

Obi, O.F., 2016. Hand anthropometry survey of rural farm workers in south-eastern Nigeria. Ergonomics, 59: 603-611.

DOI: $10.1080 / 00140139.2015 .1073796$

Okunribido, O.O., 2000. A survey of hand anthropometry of female rural farm workers in Ibadan, Western Nigeria. Ergonomics, 43: 282-292. DOI: $10.1080 / 001401300184611$

Schmidtke, H., 1984. Ergonomics and Equipment Design. In: Ergonomic Data for Equipment Design, Schmidtke, H. (Ed.), Springer US, pp: 1-13. ISBN: 978-1-4684-4906-8

SPSS Statistics 21 (incl. AMOS) for Windows/Mac, n.d.

Sutjana, D., M. Sutajaya, S. Purnawati, P. Adiatmika and K. Tunas et al., 2008. Preliminary anthropometric data of medical students for equipment applications. J. Human Ergology, 37: 45-48. DOI: $10.11183 /$ jhe 1972.37 .45

Syuaib, M.F., 2015. Anthropometric study of farm workers on Java Island, Indonesia and its implications for the design of farm tools and equipment. Applied Ergonomics, 51: 222-235. DOI: $10.1016 /$ j.apergo.2015.05.007

Wagner, C., 1988. The pianist's hand: Anthropometry and biomechanics. Ergonomics, 31: 97-131. DOI: 10.1080/00140138808966651 